\title{
A single antenatal course of betamethasone adversely affects glucose regulation in adulthood and the next generation in childhood
}

\author{
Sarah Mathai, , José Derraik, Wayne Cutfield, Stuart Dalziel, Janene Biggs, Craig Jefferies, Jane Harding, \\ Paul Hofman
}

From 8th APPES Biennial Scientific Meeting

Darwin, Australia. 29 October - 1 November 2014

\section{Objective}

To assess whether a single antenatal course of betamethasone affects insulin sensitivity and other metabolic parameters in the offspring, and whether effects are transmitted to the next generation.

\section{Methods}

A cohort of 52 adults (aged 35.7 years, $46 \%$ men, 23 born after steroid treatment) and their term-born children $(\mathrm{n}=61$, aged 8.0 years, $52 \%$ boys, $49 \%$ from a parent born after steroid treatment), was recruited in Auckland. Insulin sensitivity and secretion were assessed using hyperglycaemic clamps in adults, and HOMA-IR in children. Other assessments included DXA-derived body composition, lipid profile, adipokines, and 24-hour ambulatory blood pressure monitoring.

\section{Results}

Insulin sensitivity over the last 60 minutes of the hyperglycaemic clamp was $31 \%$ lower in the Steroid group $(\mathrm{p}=0.048)$, with a similar trend for overall insulin sensitivity $(\mathrm{p}=0.061)$. Steroid adults had a compensatory increase in first-phase insulin that was $53 \%$ higher than in controls $(\mathrm{p}=0.031)$, with total insulin secretion $44 \%$ higher in the Steroid group $(\mathrm{p}=0.044)$. Children of parents born after steroid treatment had higher fasting glucose $(\mathrm{p}=0.049)$ and

Table 1 Study outcomes in the offspring (adults, F1) born from mothers who were either treated with antenatal betamethasone (Steroid) or not treated (Control), and in subsequent generation (children, F2). Data are means and $\mathbf{9 5 \%} \mathrm{Cl}$, adjusted for confounders.

\begin{tabular}{lllll}
\hline & & Steroid & Control & p-value \\
\hline Adults (F1) & $\mathrm{n}$ & 23 & 29 & \\
& $1^{\text {st }}$ phase insulin (mU/l) & $43.1(30.9-60.2)$ & $28.1(20.9-37.8)$ & 0.031 \\
& $2^{\text {nd }}$ phase insulin (mU/l) & $57.5(42.6-77.8)$ & $41.6(31.8-54.4)$ & 0.068 \\
& Total insulin (mU/l) & $101.7(74.7-138.4)$ & $70.4(53.5-92.6)$ & 0.044 \\
& Insulin sensitivity & $16.1(11.0-22.4)$ & $23.1(17.3-30.2)$ & 0.061 \\
& Insulin sensitivity last 60 min & $14.3(9.9-19.7)$ & $20.6(15.7-26.6)$ & 0.048 \\
\hline Children (F2) & $\mathrm{n}$ & 30 & 31 & 0.049 \\
& Fasting glucose (mg/dl) & $4.88(4.69-5.12)$ & $4.67(4.50-4.85)$ & 0.008 \\
& Fasting insulin (mU/l) & $5.05(3.98-6.41)$ & $3.57(2.79-4.58)$ & 0.006 \\
\hline
\end{tabular}

\footnotetext{
Liggins Institute, University of Auckland, Auckland, New Zealand
} 
insulin ( $\mathrm{p}=0.008)$ concentrations than controls. HOMA-IR values indicated that children in the Steroid group were more insulin resistant than controls $(\mathrm{p}=0.006)$.

\section{Conclusion}

This study shows that maternal treatment with a single dose of betamethasone is associated with reduced insulin sensitivity in the offspring in mid-adulthood. Importantly, there is indication of an inter-generational effect, with the subsequent generation displaying increased insulin resistance.

Published: 28 April 2015

doi:10.1186/1687-9856-2015-S1-022

Cite this article as: Mathai et al:: A single antenatal course of

betamethasone adversely affects glucose regulation in adulthood and

the next generation in childhood. International Journal of Pediatric

Endocrinology 2015 2015(Suppl 1):O22.

Submit your next manuscript to BioMed Central and take full advantage of:

- Convenient online submission

- Thorough peer review

- No space constraints or color figure charges

- Immediate publication on acceptance

- Inclusion in PubMed, CAS, Scopus and Google Scholar

- Research which is freely available for redistribution 